\title{
Implications for selecting local excision in locally advanced rectal cancer after preoperative chemoradiation
}

\author{
Juefeng Wan ${ }^{1,2, *}$, Kaitai Liu' ${ }^{3, *}$, Ji Zhu ${ }^{1,2}$, Guichao $\mathrm{Li}^{1,2}$, Zhen Zhang ${ }^{1,2}$ \\ ${ }^{1}$ Department of Radiation Oncology, Fudan University Shanghai Cancer Center, Shanghai, China \\ ${ }^{2}$ Department of Oncology, Shanghai Medical College, Fudan University, Shanghai, China \\ ${ }^{3}$ Department of Radiation Oncology, Lihuili Hospital, Ningbo Medical Center, Ningbo, China \\ *These authors have contributed equally to this work
}

Correspondence to:

Zhen Zhang, e-mail: zhenzhang6@hotmail.com

Keywords: rectal cancer, local excision, positive lymph nodes, chemoradiotherapy, seer

Received: January 28, 2015

Accepted: February 19, 2015

Published: March 23, 2015

\section{ABSTRACT}

Local excision may offer the possibility of organ preservation for the management of locally advanced rectal cancer after neoadjuvant chemoradiotherapy (CRT). However, the oncological outcomes of this strategy have been largely associated with the risk of nodal metastases. In this study, Surveillance, Epidemiology, and End Results Program (SEER)-registered rectal cancer patients, and patients from Fudan University Shanghai Cancer Center (FUSCC) after preoperative chemoradiation were combined to analyze the incidence of lymph node metastasis. The results showed that there was a high risk for residual lymph node metastasis among patients even with complete pathologic response of primary tumor after preoperative CRT (12.6-13.2\%). However, in the selected group of patients with pre-CRT MRI staging cNO rectal cancer, there was only one ypN+ case (3.3\%) in ypT0-1 group. These results suggest that pre-CRT MRI staging cNO patients achieved ypT0-1 of bowel wall tumor may be suitable for local resection.

\section{INTRODUCTION}

Neoadjuvant chemoradiotherapy (CRT) followed by total mesorectal excision (TME) is a standard treatment in patients with locally advanced rectal cancer (LARC) [1-5]. However, radical surgery is associated with significant morbidity, especially in cases of low rectal cancer $[6,7]$. Local excision may offer the possibility of organ preservation for the management of select patients after neoadjuvant chemoradiation.

However, the oncological outcomes of this strategy have been largely associated with the risk of nodal metastases. Therefore, cautious and strict patient selection is crucial in this approach. Ideal candidate tumors for this treatment approach should be restricted to the bowel wall and harbor minimal risk for lymph nodes (LNs) metastases. Given the growing importance of lymph node metastases in the management of local excision, we designed our study to specifically assess the incidence of the positive lymph nodes in patients with locally advanced rectal cancer after chemoradiation by analyzing the Surveillance, Epidemiology, and End Results (SEER)-registered database. Moreover, because SEER data lacks information on pre-CRT clinical stage, neoadjuvant chemoradiotherapy (NCRT) methods, we further clarified these relevant issues in another set of patients with locally advanced rectal cancer from the Fudan University Shanghai Cancer Center (FUSCC).

\section{RESULTS}

\section{SEER database patient characteristics}

A total of 12,682 eligible patients during the 8 -year study period were indentified, including 7,982 male and 4,700 female patients. There were 114 patients $(0.9 \%)$ with ypT0 stage, 1091 patients $(8.6 \%)$ with ypT1 stage, 1989 patients (15.7\%) with ypT2 stage, and 9488 patients (74.8\%) with ypT3-4 stage rectal cancer. Patient demographics and pathological features are summarized in Table 1. The proportion of well differentiation (Grade I) gradually decreased from ypT0 to ypT3/4 (10.5\% to $6.1 \%)$. 
Table 1: Patient characteristics from SEER database

\begin{tabular}{|c|c|c|c|c|c|c|c|c|}
\hline \multirow[b]{2}{*}{ Variable } & \multicolumn{2}{|c|}{ урТ0 } & \multicolumn{2}{|c|}{ урТ1 } & \multicolumn{2}{|c|}{ урТ2 } & \multicolumn{2}{|c|}{ урТ3-4 } \\
\hline & $\mathbf{n}$ & $\%$ & $\mathbf{n}$ & $\%$ & $\mathbf{n}$ & $\%$ & $\mathbf{n}$ & $\%$ \\
\hline \multicolumn{9}{|l|}{ Sex } \\
\hline Male & 74 & 64.9 & 692 & 63.4 & 1297 & 65.2 & 5919 & 62.4 \\
\hline Female & 40 & 35.1 & 399 & 36.6 & 692 & 34.8 & 3569 & 37.6 \\
\hline \multicolumn{9}{|l|}{ Age } \\
\hline$<50$ & 20 & 17.5 & 195 & 17.9 & 377 & 19 & 1933 & 20.4 \\
\hline$\geq 50$ & 94 & 82.5 & 896 & 82.1 & 1612 & 81 & 7555 & 79.6 \\
\hline \multicolumn{9}{|l|}{ Race } \\
\hline White & 99 & 86.8 & 910 & 83.4 & 1604 & 80.6 & 7764 & 81.8 \\
\hline Black & 8 & 7 & 97 & 8.9 & 188 & 9.5 & 729 & 7.7 \\
\hline Other & 7 & 6.2 & 84 & 7.7 & 197 & 9.9 & 995 & 10.5 \\
\hline \multicolumn{9}{|c|}{ Pathological grading } \\
\hline Grade I & 12 & 10.5 & 89 & 8.2 & 127 & 6.4 & 581 & 6.1 \\
\hline Grade II & 63 & 55.3 & 707 & 64.8 & 1459 & 73.4 & 6474 & 68.2 \\
\hline Grade III & 11 & 9.6 & 95 & 8.7 & 190 & 9.6 & 1273 & 13.4 \\
\hline Grade IV & 2 & 1.8 & 5 & 0.5 & 8 & 0.4 & 111 & 1.2 \\
\hline Unknown & 26 & 22.8 & 195 & 17.8 & 205 & 10.2 & 1049 & 11.1 \\
\hline \multicolumn{9}{|l|}{ Histotype } \\
\hline Adenocarcinoma & 109 & 95.6 & 1058 & 97 & 1911 & 96.1 & 8685 & 91.5 \\
\hline $\begin{array}{l}\text { Mucinous/ } \\
\text { Signet ring cell }\end{array}$ & 5 & 44 & 33 & 3 & 78 & 3.9 & 803 & 8.5 \\
\hline \multicolumn{9}{|l|}{ LNs examined } \\
\hline Median & 6 & & 8 & & 11 & & 12 & \\
\hline Rang & $1-21$ & & $1-25$ & & $1-28$ & & $1-35$ & \\
\hline
\end{tabular}

Abbreviations: LNs, lymph nodes.

\section{Incidence of positive lymph nodes}

Overall, 5649(44.5\%) patients had lymph node metastasis. Patients with higher ypT categories following chemoradiotherapy were more likely to also have positive ypN status $(P<0.001)$. By ypT stage, the numbers of ypN+ tumors were $15(13.2 \%)$ for ypT0, $186(17 \%)$ for ypT1, $618(31 \%)$ for ypT2, and $4830(50.9 \%)$ for ypT3/4. Patients were categorized into two groups based on the identification of lymph nodes metastasis: ypN0 and ypN+ (Table 2).

\section{Study of potential associations}

To discard potential bias in the detection of pathologically positive LNs, we studied possible associations between patient and tumor characteristics (Table 2). Sex did not correlate with ypN+ $(P=0.706)$, because $3530(44.2 \%)$ of 7982 male patients had ypN+ compared with 2119 (45.1\%) of 4700 female patients. As seen in Table 2 , the rate of $\mathrm{ypN}+$ did differ significantly between adenocarcinoma (43.4\%) and mucinous/signet ring cell $(59.7 \% ; P<0.001)$. In addition, the race was not found to be significantly associated with the incidence of ypN+ $(P=0.305)$.

\section{Evaluating the SEER database outcomes using the fusce set}

The above results should be treated with caution as they might be biased by confounding factors, such as pre-CRT stage and concurrent chemotherapy. To evaluate the reliability of SEER results, we studied relevant issues in 517 eligible patients from the FUSCC. 
Table 2: Association of positive nodes with clinical/pathologic variables from SEER database

\begin{tabular}{|c|c|c|c|c|c|}
\hline & \multicolumn{2}{|c|}{$\mathbf{L N}-$} & \multicolumn{2}{|c|}{$\mathbf{L N}+$} & \multirow[b]{2}{*}{$\mathbf{P}$} \\
\hline Variable & $\mathbf{n}$ & $\%$ & $\mathbf{n}$ & $\%$ & \\
\hline \multicolumn{6}{|l|}{ Sex } \\
\hline Male & 4452 & 55.8 & 3530 & 44.2 & \multirow{2}{*}{0.706} \\
\hline Female & 2581 & 54.9 & 2119 & 45.1 & \\
\hline \multicolumn{6}{|l|}{ Age } \\
\hline$<50$ & 1182 & 46.8 & 1343 & 53.2 & \multirow{2}{*}{$<0.001$} \\
\hline$\geq 50$ & 5851 & 57.6 & 4306 & 42.4 & \\
\hline \multicolumn{6}{|l|}{ Race } \\
\hline White & 5804 & 55.9 & 4573 & 44.1 & \multirow{3}{*}{0.305} \\
\hline Black & 569 & 55.7 & 453 & 44.3 & \\
\hline other & 660 & 51.4 & 623 & 48.6 & \\
\hline \multicolumn{6}{|c|}{ Pathological grading } \\
\hline Grade I & 449 & 61.7 & 310 & 38.3 & \multirow{5}{*}{0.017} \\
\hline Grade II & 4943 & 56.8 & 3760 & 43.2 & \\
\hline Grade III & 680 & 43.3 & 889 & 56.7 & \\
\hline Grade IV & 42 & 33.3 & 84 & 66.7 & \\
\hline unknown & 869 & 58.9 & 606 & 41.1 & \\
\hline \multicolumn{6}{|l|}{ Histotype } \\
\hline Adenocarcinoma & 6663 & 56.6 & 5100 & 43.4 & $<0.001$ \\
\hline $\begin{array}{l}\text { Mucinous/ } \\
\text { Signet ring cell }\end{array}$ & 370 & 40.3 & 549 & 59.7 & \\
\hline \multicolumn{6}{|l|}{ ypT } \\
\hline 0 & 99 & 86.8 & 15 & 13.2 & \multirow{4}{*}{$<0.001$} \\
\hline 1 & 905 & 83 & 186 & 17 & \\
\hline 2 & 1371 & 69 & 618 & 31 & \\
\hline $3 / 4$ & 4658 & 49.1 & 4830 & 50.9 & \\
\hline \multicolumn{6}{|l|}{ LNs examined } \\
\hline Median & 10 & & 13 & & \multirow{2}{*}{$<0.001$} \\
\hline Rang & $1-27$ & & $1-35$ & & \\
\hline
\end{tabular}

Abbreviations: LNs, lymph nodes.

Patient demographics and pathological features are summarized in Table 3.

\section{Incidence of positive LNs}

In 193 of 517 patients $(37.3 \%)$, routine pathologic analysis of the resected specimen revealed positive LN involvement. Patients with higher ypT categories following chemoradiotherapy were more likely to also have positive ypN status $(P<0.001)$. By ypT stage, the numbers of ypN+ tumors were $14(12.6 \%)$ for ypT0, $6(19.4 \%)$ for ypT1, $38(31.9 \%)$ for ypT2, and $135(52.7 \%)$ for ypT3/4. In addition, we assessed the rate of positive LN involvement according to the pre-CRT MRI staging. Our findings showed that the proportion of lymph node metastasis in ypT0-1 cases was $17 \%$ among pre-CRT MRI staging $\mathrm{cN}+$ patients. In the selected group of patients with pre-CRT MRI staging cN0 rectal cancer, there was 
Table 3: Demographic and clinical features of patients with rectal cancer from Fudan University Shanghai Cancer Center

\begin{tabular}{|c|c|c|c|c|c|c|c|c|}
\hline & \multicolumn{2}{|c|}{ урТ0 } & \multicolumn{2}{|c|}{ ypT1 } & \multicolumn{2}{|c|}{ урT2 } & \multicolumn{2}{|c|}{ урТ3-4 } \\
\hline Variable & $\mathbf{n}$ & $\%$ & $\mathbf{n}$ & $\%$ & $\mathbf{n}$ & $\%$ & $\mathbf{n}$ & $\%$ \\
\hline \multicolumn{9}{|l|}{ Sex } \\
\hline Male & 78 & 70.3 & 23 & 74.2 & 74 & 62.2 & 185 & 72.3 \\
\hline Female & 33 & 29.7 & 8 & 25.8 & 45 & 37.8 & 71 & 27.7 \\
\hline \multicolumn{9}{|l|}{ Age } \\
\hline$<50$ & 40 & 36 & 8 & 25.8 & 37 & 31.1 & 77 & 30.1 \\
\hline$\geq 50$ & 71 & 64 & 23 & 74.2 & 82 & 68.9 & 179 & 69.9 \\
\hline \multicolumn{9}{|l|}{ Baseline stage } \\
\hline II & 23 & 20.7 & 7 & 22.6 & 19 & 16 & 43 & 16.8 \\
\hline III & 88 & 79.3 & 24 & 77.4 & 100 & 84 & 213 & 83.2 \\
\hline \multicolumn{9}{|c|}{ Distance from anal verge } \\
\hline$\leq 5 \mathrm{~cm}$ & 73 & 65.8 & 20 & 64.5 & 76 & 63.9 & 142 & 55.5 \\
\hline$>5 \mathrm{~cm}$ & 38 & 34.2 & 11 & 35.5 & 43 & 36.1 & 114 & 44.5 \\
\hline \multicolumn{9}{|l|}{ LNs examined } \\
\hline Median & 9 & & 9 & & 10 & & 10 & \\
\hline Range & $1-24$ & & $4-20$ & & $2-27$ & & $1-28$ & \\
\hline \multicolumn{9}{|l|}{ CCT } \\
\hline $\begin{array}{l}\text { fluorouracil } \\
\text { alone }\end{array}$ & 39 & 35.1 & 11 & 35.5 & 36 & 30.3 & 112 & 43.8 \\
\hline FBCR & 72 & 64.9 & 20 & 64.5 & 83 & 69.7 & 144 & 56.2 \\
\hline
\end{tabular}

Abbreviations: LNs, lymph nodes; FBCR, fluorouracil-based combination regimens; CCT, concurrent chemotherapy.

only one ypN+ case $(3.3 \%)$ which was tumor nodules rather than lymph node in ypT0-1 group. Patients were categorized into two groups based on the identification of lymph node metastasis: ypN0 and ypN+ (Table 3).

\section{Study of potential associations}

To discard potential bias in the detection of pathologically positive LNs, we studied possible associations between patient and tumor characteristics, concurrent chemotherapy regimens (Table 4). Distance from the anal verge did not correlate with ypN+ $(P=0.691)$, because $114(36.7 \%)$ of 311 patients with tumors located 0 to $5 \mathrm{~cm}$ from the anal verge had ypN+ compared with $79(38.3 \%)$ of 206 patients with tumors located 6 to $12 \mathrm{~cm}$ from the anal verge. As seen in Table 4, the rate of $y p N+$ did not differ significantly between different concurrent chemotherapy (fluorouracil alone or fluorouracil-based combination regimens) $(P=0.697)$.

\section{DISCUSSION}

Chemoradiotherapy (CRT) followed by total mesorectal excision was considered the standard of care in the treatment of locally advanced rectal cancer since it was proven to be beneficial in reducing the rate of local recurrence and toxicity [1-5]. In order to avoid the potential morbidity and impaired long-term functional outcomes associated with radical resection, there has been an increasing interest for organ-preserving strategies with local excision in the management of patients with rectal cancer and good response to neoadjuvant CRT.

Local excision of rectal tumors is a technique with significant lower morbidity and mortality rates, compared with standard radical surgery $[8,9]$. Stipa et al. evaluated the long-term clinical outcome of a selected group of 43 patients who underwent local excision with transanal endoscopic microsurgery after chemoradiation. In the ypT0 group, no local and distal recurrences were observed. In the ypT1-3 group, local recurrence was 10/30 (33\%) [10]. 
Table 4: Association of positive nodes with clinical/pathologic variables from fudan university shanghai cancer center

\begin{tabular}{|c|c|c|c|c|c|}
\hline & \multicolumn{2}{|c|}{$\mathbf{L N}-$} & \multicolumn{2}{|c|}{$\mathbf{L N}+$} & \multirow[b]{2}{*}{$\mathbf{P}$} \\
\hline Variable & $\mathbf{n}$ & $\%$ & $\mathbf{n}$ & $\%$ & \\
\hline \multicolumn{6}{|l|}{ Age (yr) } \\
\hline Median & 56 & & 56 & & 0.002 \\
\hline Range & $26-77$ & & $20-82$ & & \\
\hline \multicolumn{6}{|l|}{ Gender } \\
\hline Male & 236 & 65.6 & 124 & 34.3 & 0.04 \\
\hline Female & 88 & 56.1 & 69 & 43.9 & \\
\hline \multicolumn{6}{|c|}{ Distance from anal verge } \\
\hline Median & 5 & & 5 & & 0.691 \\
\hline Range & $1-12$ & & $0-12$ & & \\
\hline$\leq 5 \mathrm{~cm}$ & 197 & 63.3 & 114 & 36.7 & \\
\hline$>5 \mathrm{~cm}$ & 127 & 61.7 & 79 & 38.3 & \\
\hline \multicolumn{6}{|l|}{ CCT } \\
\hline $\begin{array}{l}\text { fluorouracil } \\
\text { alone }\end{array}$ & 122 & 61.6 & 76 & 38.4 & 0.697 \\
\hline FBCR & 202 & 63.3 & 117 & 36.8 & \\
\hline \multicolumn{6}{|l|}{ YPT } \\
\hline 0 & 97 & 87.4 & 14 & 12.6 & $<0.001$ \\
\hline 1 & 25 & 80.6 & 6 & 19.4 & \\
\hline 2 & 81 & 68.1 & 38 & 31.9 & \\
\hline $3 / 4$ & 121 & 47.3 & 135 & 52.7 & \\
\hline \multicolumn{6}{|c|}{ ypT, pre-CRT stage (N0) } \\
\hline 0 & 22 & 95.7 & 1 & 4.3 & 0.017 \\
\hline 1 & 7 & 100 & 0 & 0 & \\
\hline 2 & 17 & 81 & 4 & 19 & \\
\hline $3 / 4$ & 30 & 71.4 & 12 & 28.6 & \\
\hline \multicolumn{6}{|c|}{ ypT, pre-CRT stage $(\mathrm{N}+)$} \\
\hline 0 & 75 & 85.2 & 13 & 14.8 & $<0.001$ \\
\hline 1 & 18 & 75 & 6 & 25 & \\
\hline 2 & 64 & 65.3 & 34 & 34.7 & \\
\hline $3 / 4$ & 91 & 42.5 & 123 & 57.5 & \\
\hline
\end{tabular}

Abbreviations: CRT, chemoradiotherapy; LN, lymph node; FBCR, fluorouracil-based combination regimens; CCT, concurrent chemotherapy.

In addition, Noh and colleagues reported the outcome of local excision following preoperative chemoradiotherapy for cT2 rectal cancer. The 5-year disease-free survival was higher in patients with ypT0 (90\%) than in patients with ypT1-2 (69\%, $p=0.1643)$ [11]. Moreover, Belluco et al. conducted a study on 29 patients treated by local excision, 
comparing patients with ypCR to patients with no ypCR, 5-year local recurrence-free survival was $92.9 \%$ vs. $66.7 \%$ $(P=0.047)$ [12]. Therefore, these studies suggested that TEM may have a curative role in the case of complete response to CRT.

Despite these several studies had reported that local excision in patients who showed a good response to CRT had acceptably low rates of local recurrence and long-term survival outcomes compared with radical surgery. However, the issue of local resection following preoperative CRT has been addressed by few studies, which are limited by the low numbers and short follow-up [10-13].

Although response at the primary tumor site within the bowel may provide insight into the status of residual disease within the mesorectum, one of the uncertain facts which could not be ignored when conducting local excision is the status of the mesorectal lymph nodes. Some studies have confirmed that there can be differential responses between the primary tumor and the mesorectal lymph nodes $[14,15]$. When nodal involvement is understaged and patients undergo local excision, the prognosis is poorer. Park and colleagues determined the rate of residual lymph node involvement following neoadjuvant chemoradiotherapy among patients with ypT0-2 residual bowel wall tumor [16]. Among all 406 ypT0-2 patients, 66 (16.3\%) had lymph node metastasis: $20.8 \%$ among ypT2, $17.1 \%$ among ypT1, and $9.1 \%$ among ypT0 patients. Local recurrences occurred more frequently in ypN+ vs ypN0 patients (2.0\% vs. $5.5 \% ; p=0.038)$. Recurrence-free survival was $87.5 \%$ among ypT0-2N0 and $83.6 \%$ forypT0-2N+ $(P=0.28)$. With the $\mathrm{T}$ staging, lymph node metastasis rate also increased. In the present study, the SEER data showed that lymph node metastasis was $31 \%$ among ypT2, 17\% among ypT1, and 13.2\% among ypT0 patients. Patient data from FUSCC showed that the incidence of lymph node involvement was $12.6 \%$ in patients developing mural pCR (ypT0) compared to $19.4 \%$ for $\mathrm{ypT} 1$ and increased further to $31.9 \%$ for ypT2 tumors which was comparable to the SEER data. These data showed that the incidence of lymph node involvement was more than $10 \%$ in patients with complete response of primary tumor.

Recently, a randomized trial of patients with cT2N0 following preoperative CRT to either TME or local excision (using transanal endoscopic microsurgery, TEM) suggested equivalent local disease control with both techniques [17]. The risk of lymph node metastases after CRT is already minimized when proper staging at baseline shows cN0. Based on this, perhaps baseline lymph node staging may play a significant role in predicting the risk of lymph node metastases after CRT. Guillem et al. showed the incidence of positive LNs in patients with pre-CRT stage cT3N0 after
CRT: ypT0, 3\%; ypT1, 7\%; урT2, 20\%; ypT3-4, 36\% $(P=.001)$ which was significantly lower than patient with cT3, 4N+ [18]. In the present study, we assessed the rate of positive $\mathrm{LN}$ involvement according to the pre-CRT MRI staging. Our findings showed that the proportion of lymph node metastasis in ypT0-1 cases was $17 \%$ among pre-CRT MRI staging $\mathrm{cN}+$ patients. In the selected group of patients with pre-CRT MRI staging $\mathrm{cN} 0$ rectal cancer, there was only one ypN+ case $(3.3 \%)$ which was tumor nodule rather than lymph node in ypT0-1 group.

MRI has been used to delineate locally stage non-irradiated rectal cancers. Recently, several studies have shown that the use of MRI improves the overall $\mathrm{T}$ staging accuracy for rectal cancer with accuracy rates of 86\%-95\% [19-21]. Regarding LN assessments with MRI, the sensitivity and specificity are $75 \%-89 \%$ and $71 \%-98 \%$, respectively [21-25]. Restaging MRI is performed after CRT to restage rectal cancer to identify the response of chemoradiation. Lee et al. conducted a study to evaluate the efficacy of restaging MRI for predicting the pathologic stage in rectal cancer after CRT. Pathologic T classification matched the postCRT MRI findings in $97(64.7 \%)$ of 150 patients and pathologic $\mathrm{N}$ classification matched the post-CRI MRI findings in $85(56.6 \%)$ of 150 patients [26]. In addition, Park et al. determined whether preoperative MRI could detect lymph node metastases accurately in the nodeby-node analysis [27]. Of the 341 nodes harvested, 120 were too small $(<3 \mathrm{~mm})$ to be depicted on magnetic resonance images, and 18 of these contained metastasis (15\%). Preoperative MRI revealed anode-by-node sensitivity and positive predictive value of $58.0 \%$, and $61.7 \%$. Therefore, preoperative MRI has low accuracy for the prediction of the pathologic $\mathrm{T}$ and $\mathrm{N}$ classifications in rectal cancer patients who received preoperative CRT.

Our study has several limitations that deserve mention. First, although the present study is a large population-based study, the SEER database does not include information regarding the administration of CRT and the quality of surgical care or pathological technique, and all of these factors may affect positive LNs harvest. Second, it is a retrospective analysis and was therefore limited by the bias inherent in this type of analysis. However, given that the study patients were consecutive, offering a non-selected series of $\mathrm{T} 3,4$ and/or $\mathrm{N}+$ rectal cancers, we believe that our results do not reflect a bias toward patients.

In conclusion, given use of ypT stage only to stratify patients for local excision is partly unsafe, organ-preserving strategies for these patients will need to consider baseline MRI imaging in addition to CRT response to identify eligible patients. Our study demonstrates that there was a high risk for residual lymph 
node metastasis among patients even with complete pathologic response of primary tumor after preoperative CRT (12.6-13.2\%). But if cT3,4N0 patients whom be classified according to baseline MRI imaging achieved ypT0-1 of bowel wall tumor, the rate of positive LN involvement was clinically acceptable $(3.3 \%$, tumor nodule, actually). This group of patients may be suitable for local resection. Considering that this study is a retrospective analysis, we need further prospective studies to verify.

\section{MATERIALS AND METHODS}

\section{Patient selection in the SEER database}

The SEER, a population-based reporting system, was surveyed for the retrospective collection of data used in the analysis. The SEER program collects and publishes cancer incidence and survival data from 18 populationbased cancer registries, covering $>25 \%$ of the US population. Because no personal identifying information was used in the analysis, this study was granted an exemption from the Institutional Review Board of the study institution on March 30, 2012.

Cases of rectal cancer (C20.9 Rectum, NOS) from 2004 to 2011 were extracted from the SEER database (SEER*Stat 8.1.5) according to the Site Recode classifications with limitation to radiation prior to surgery and radiation preoperatively and post-surgery. Histological type were limited to adenocarcinoma (ICD-03, 8140/3, $8210 / 3,8261 / 3,8263 / 3)$, mucinous adenocarcinoma (ICD-03, 8480/3), and signet ring cell carcinoma (ICD-03, 8490/3). We selected this range because American Joint Committee on Cancer (AJCC) TMN stage was available since 2004. Other exclusion criteria were as follows: no LNs examined pathologically, synchronous distance metastases, and patients with unknown TNM stage.

\section{Patient selection in the FUSCC}

The Fudan University Shanghai Cancer Center Ethics Review Board approved the study. Preoperative chemoradiation was performed as standard treatment of LARC since 2006, so we performed a retrospective consecutive cohort study of locally advanced rectal cancer patients with preoperative chemoradiation at FUSCC between 2006 and 2013. Patients were identified from our institutional patient colorectal cancer database. Patients with no LNs examined pathologically, synchronous distance metastases, and unknown TNM stage were excluded.

\section{Treatment details}

Pretreatment clinical stage was assessed on the basis of MRI. All pretreatment biopsies were reviewed and diagnoses confirmed by Shanghai Cancer Center gastrointestinal pathologists. All patients also underwent full colonoscopic evaluation to exclude synchronous tumors, as well as digital rectal examination and proctoscopy to identify the tumor distance from the anal verge. Patients were treated with chemoradiotherapy with a median radiotherapy dose of 50 Gy and concurrent fluorouracil-based chemotherapy. Surgery generally was performed 6 to 8 weeks following completion of chemoradiotherapy and included low anterior resection, or abdominoperineal resection using total mesorectal excision (TME) principles. Adjuvant chemotherapy consisted of FOLFOX, XELOX, or Capecitabine for a period of 4 to 5 months was recommended for all medically fit patients following resection. Standard pathologic tumor staging of the resected specimen was performed after resection in accordance with the guidelines of the College of American Pathologists, with histopathologic diagnosis performed by dedicated gastrointestinal cancer pathologists. The gross tumor volume was entirely embedded and serially sectioned for hematoxylin and eosin staining and microscopic evaluation. Postoperative follow-up consisted of routine physical examination with carcinoembryonic antigen measurement and crosssectional imaging every 3-6 months for the first 2 years after completion of treatment and every 6-12 months for 2 additional years thereafter. CT scans of the chest, abdomen and pelvis, full colonoscopic evaluation, and/or positron emission tomography (PET) were immediately performed if any symptom of disease occurred or elevated tumor marker levels were detected.

\section{Statistical analysis}

Associations between LN positivity and clinical/ pathologic variables were examined using Fisher's exact test for categoric variables, an exact version of the MantelHaenszel test for trend for ordinal variables, and the Wilcoxon test for continuous variables. The statistical test was two sided and $P<0.05$ was considered statistically significant. PASW Statistics 13 (SPSS Inc., Chicago, USA) was used for the statistical analysis.

\section{ACKNOWLEDGMENTS}

The authors acknowledge the efforts of the Surveillance, Epidemiology, and End Results (SEER) Program tumor registries in the creation of the SEER database. The interpretation and reporting of these data are the sole responsibility of the authors. The authors have no support or funding to report.

\section{Statement of author contributions}

JFW and KTL conceived of and designed the study. JFW and JZ performed the analyses. KTL and GCL 
prepared all tables. JFW, KTL, and ZZ wrote the main manuscript. All authors reviewed the manuscript.

\section{CONFLICTS OF INTEREST} interests.

The authors declare that they have no competing

\section{REFERENCES}

1. Aschele C, Cionini L, Lonardi S, Pinto C, Cordio S, Rosati G, Artale S, Tagliagambe A, Ambrosini G, Rosetti P, Bonetti A, Negru ME, Tronconi MC, Luppi G, Silvano G, Corsi DC, et al. Primary tumor response to preoperative chemoradiation with or without oxaliplatin in locally advanced rectal cancer: pathologic results of the STAR-01 randomized phase III trial. J Clin Oncol. 2011; 29:2773-2780.

2. Gerard JP, Azria D, Gourgou-Bourgade S, Martel-Laffay I, Hennequin C, Etienne PL, Vendrely V, Francois E, de La Roche G, Bouche O, Mirabel X, Denis B, Mineur L, Berdah JF, Mahe MA, Becouarn Y, et al. Comparison of two neoadjuvant chemoradiotherapy regimens for locally advanced rectal cancer: results of the phase III trial ACCORD 12/0405-Prodige 2. J Clin Oncol. 2010; 28:1638-1644.

3. Rodel C, Liersch T, Becker H, Fietkau R, Hohenberger W, Hothorn T, Graeven U, Arnold D, Lang-Welzenbach M, Raab HR, Sulberg H, Wittekind C, Potapov S, Staib L, Hess C, Weigang-Kohler $\mathrm{K}$, et al. Preoperative chemoradiotherapy and postoperative chemotherapy with fluorouracil and oxaliplatin versus fluorouracil alone in locally advanced rectal cancer: initial results of the German CAO/ARO/AIO-04 randomised phase 3 trial. Lancet Oncol. 2012; 13:679-687.

4. Sauer R, Becker H, Hohenberger W, Rodel C, Wittekind C, Fietkau R, Martus P, Tschmelitsch J, Hager E, Hess CF, Karstens JH, Liersch T, Schmidberger H, Raab R. Preoperative versus postoperative chemoradiotherapy for rectal cancer. N Engl J Med. 2004; 351:1731-1740.

5. Sauer R, Liersch T, Merkel S, Fietkau R, Hohenberger W, Hess C, Becker H, Raab HR, Villanueva MT, Witzigmann H, Wittekind C, Beissbarth T, Rodel C. Preoperative versus postoperative chemoradiotherapy for locally advanced rectal cancer: results of the German $\mathrm{CAO} /$ ARO/AIO-94 randomized phase III trial after a median follow-up of 11 years. J Clin Oncol. 2012; 30:1926-1933.

6. Chessin DB, Enker W, Cohen AM, Paty PB, Weiser MR, Saltz L, Minsky BD, Wong WD, illem JG. Complications after preoperative combined modality therapy and radical resection of locally advanced rectal cancer: a 14-year experience from a specialty service. J Am Coll Surg. 2005; 200:876-882.

7. Hendren SK, O'Connor BI, Liu M, Asano T, Cohen Z, Swallow CJ, Macrae HM, Gryfe R, Leod RS. Prevalence of male and female sexual dysfunction is high following surgery for rectal cancer. Ann Surg. 2005; 242:212-223.

8. Sajid MS, Farag S, Leung P, Sains P, Miles WF, Baig MK. Systematic review and meta-analysis of published trials comparing the effectiveness of transanal endoscopic microsurgery and radical resection in the management of early rectal cancer. Colorectal Dis. 2014; 16:2-14.

9. Ung L, Chua TC, Engel AF. A systematic review of local excision combined with chemoradiotherapy for early rectal cancer. Colorectal Dis. 2014; 16:502-515.

10. Stipa F, Picchio M, Burza A, Soricelli E, Vitelli CE. Long-term outcome of local excision after preoperative chemoradiation for ypT0 rectal cancer. Dis Colon Rectum. 2014; 57:1245-1252.

11. Noh JM, Park W, Kim JS, Koom WS, Kim JH, Choi DH, Park HC. Outcome of Local Excision Following Preoperative Chemoradiotherapy for Clinically T2 Distal Rectal Cancer: A Multicenter Retrospective Study (KROG 12-06). Cancer Res Treat. 2014; 46:243-249.

12. Belluco C, De Paoli A, Canzonieri V, Sigon R, Fornasarig M, Buonadonna A, Boz G, Innocente R, Perin T, Cossaro M, Polesel J, De Marchi F. Long-term outcome of patients with complete pathologic response after neoadjuvant chemoradiation for cT3 rectal cancer: implications for local excision surgical strategies. Ann Surg Oncol. 2011; 18:3686-3693.

13. Perez RO, Habr-Gama A, Sao Juliao GP, Proscurshim I, Coelho AQ, Figueiredo MN, Fernandez LM, Gama-Rodrigues J. Transanal local excision for distal rectal cancer and incomplete response to neoadjuvant chemoradiation - does baseline staging matter?. Dis Colon Rectum. 2014; 57:1253-1259.

14. Park IJ, Yu CS. Current issues in locally advanced colorectal cancer treated by preoperative chemoradiotherapy. World J Gastroenterol. 2014; 20:2023-2029.

15. Bujko K, Richter P, Smith FM, Polkowski W, Szczepkowski M, Rutkowski A, Dziki A, Pietrzak L, Kolodziejczyk M, Kusnierz J, Gach T, Kulig J, Nawrocki G, Radziszewski J, Wierzbicki R, Kowalska T, et al. Preoperative radiotherapy and local excision of rectal cancer with immediate radical re-operation for poor responders: a prospective multicentre study. Radiother Oncol. 2013; 106:198-205.

16. Park IJ, You YN, Skibber JM, Rodriguez-Bigas MA, Feig B, Nguyen S, Hu CY, Chang GJ. Comparative analysis of lymph node metastases in patients with ypT0-2 rectal cancers after neoadjuvant chemoradiotherapy. Dis Colon Rectum. 2013; 56:135-141.

17. Lezoche E, Baldarelli M, Lezoche G, Paganini AM, Gesuita R, Guerrieri M. Randomized clinical trial of endoluminal locoregional resection versus laparoscopic total mesorectal excision for T2 rectal cancer after neoadjuvant therapy. Br J Surg. 2012; 99:1211-1218. 
18. Guillem JG, Diaz-Gonzalez JA, Minsky BD, Valentini V, Jeong SY, Rodriguez-Bigas MA, Coco C, Leon R, Hernandez-Lizoain JL, Aristu JJ, Riedel ER, Nitti D, Wong WD, Pucciarelli S. cT3N0 rectal cancer: potential overtreatment with preoperative chemoradiotherapy is warranted. J Clin Oncol. 2008; 26:368-373.

19. Winter L, Bruhn H, Langrehr J, Neuhaus P, Felix R, Hanninen LE. Magnetic resonance imaging in suspected rectal cancer: determining tumor localization, stage, and sphincter-saving resectability at 3-Tesla-sustained high resolution. Acta Radiol. 2007; 48:379-387.

20. Futterer JJ, Yakar D, Strijk SP, Barentsz JO. Preoperative 3T MR imaging of rectal cancer: local staging accuracy using a two-dimensional and three-dimensional T2-weighted turbo spin echo sequence. Eur J Radiol. 2008; 65:66-71.

21. Sani F, Foresti M, Parmiggiani A, D'Andrea V, Manenti A, Amorotti C, Scotti R, Gallo E, Torricelli P. 3-T MRI with phased-array surface coil in the local staging of rectal cancer. Radiol Med. 2011; 116:375-388.

22. Brown G, Richards CJ, Bourne MW, Newcombe RG, Radcliffe AG, Dallimore NS, Williams GT. Morphologic predictors of lymph node status in rectal cancer with use of high-spatial-resolution MR imaging with histopathologic comparison. Radiology. 2003; 227:371-377.
23. Al-Sukhni E, Milot L, Fruitman M, Beyene J, Victor JC, Schmocker S, Brown G, McLeod R, Kennedy E. Diagnostic accuracy of MRI for assessment of T category, lymph node metastases, and circumferential resection margin involvement in patients with rectal cancer: a systematic review and metaanalysis. Ann Surg Oncol. 2012; 19:2212-2223.

24. Bipat S, Glas AS, Slors FJ, Zwinderman AH, Bossuyt PM, Stoker J. Rectal cancer: local staging and assessment of lymph node involvement with endoluminal US, CT, and MR imaging — a meta-analysis. Radiology. 2004; 232:773-783.

25. Kim DJ, Kim JH, Lim JS, Yu JS, Chung JJ, Kim MJ, Kim KW. Restaging of Rectal Cancer with MR Imaging after Concurrent Chemotherapy and Radiation Therapy. Radiographics. 2010; 30:503-516.

26. Lee JH, Jang HS, Kim JG, Lee MA, Kim DY, Kim TH, Oh JH, Park SC, Kim SY, Baek JY, Park HC, Kim HC, Nam TK, Chie EK, Jung JH, Oh ST. Prediction of pathologic staging with magnetic resonance imaging after preoperative chemoradiotherapy in rectal cancer: pooled analysis of KROG 10-01 and 11-02. Radiother Oncol. 2014; 113:18-23.

27. Park JS, Jang YJ, Choi GS, Park SY, Kim HJ, Kang H, Cho SH. Accuracy of preoperative MRI in predicting pathology stage in rectal cancers: node-for-node matched histopathology validation of MRI features. Dis Colon Rectum. 2014; 57:32-38. 